\title{
Warfarin-induced calciphylaxis: a case report and review of literature
}

This article was published in the following Dove Press journal:

International Journal of General Medicine

8 August 2013

Number of times this article has been viewed

\section{Chadi Saifan \\ Marc Saad \\ Elie El-Charabaty \\ Suzanne El-Sayegh}

Staten Island University Hospital, Staten Island, NY, USA
Correspondence: Chadi Saifan Staten Island University Hospital, 475 Seaview Avenue, Staten Island, NY 10305, USA

$\mathrm{Tel}+17182269000$

Fax + I 7182266586

Email chadisaifan@hotmail.com
Abstract: Calciphylaxis is a challenging complication of end-stage renal disease, with an unknown underlying mechanism. Several risk factors have been identified, such as hyperphosphatemia, hypercalcemia, hyperparathyroidism, low serum albumin levels, and history of warfarin therapy. This article presents a case of calciphylaxis provoked by reintroduction of warfarin therapy, introducing the possibility of direct induction.

Keywords: warfarin, calciphylaxis, skin necrosis, ESRD

\section{Introduction}

Calciphylaxis is a rare complication of end-stage renal disease estimated to occur in $1 \%-4 \%$ of patients on hemodialysis, ${ }^{1}$ and has a high mortality rate. ${ }^{2-4}$ Treatment is still challenging, as the mechanism of occurrence has not yet been identified. Risk factors, to summarize, can be categorized into several groups, such as local factors in adipose tissue, disturbance in mineral and bone metabolism, renal failure, gender, diabetes, inflammatory conditions, and others. ${ }^{2-5}$

Warfarin, a vitamin $\mathrm{K}$ antagonist, has been implicated in the calcification process and has been reported to be a risk factor for calciphylaxis. ${ }^{1-9}$ Though many have reported warfarin as a risk factor for calciphylaxis, we are reporting a case of calciphylaxis occurring briefly after restarting warfarin therapy, calling warfarin into question as a precipitating event in the mechanism of calciphylaxis.

\section{Discussion}

Calciphylaxis, also called calcific uremic arteriolopathy, is a rare complication of end-stage renal disease with high morbidity and mortality rates of $60 \%-80 \%$, often from sepsis. ${ }^{2,3,5}$

The term calciphylaxis was initially used to describe an acute calcification process in rodents believed to be an induced hypersensitivity reaction in previously sensitized tissue. $^{2}$

The diagnosis of calciphylaxis was based on the clinical description of necrotic and painful skin ulceration and the histopathology findings of medial calcification and intimal proliferation of small ${ }^{2,3,5}$ and medium-sized ${ }^{5}$ arteries, primarily in dermal and subcutaneous tissues (Figures 1, 2 and 3). ${ }^{5}$ Endovascular fibrosis and microthrombi contribute to tissue ischemia, ${ }^{5}$ promoting occlusion and subsequent livedoid necrosis and ulceration. ${ }^{4}$

The differential diagnosis for a cutaneous lesion in a hemodialysis patient includes vasculitis, cholesterol embolization syndrome, calciphylaxis, warfarin-induced 

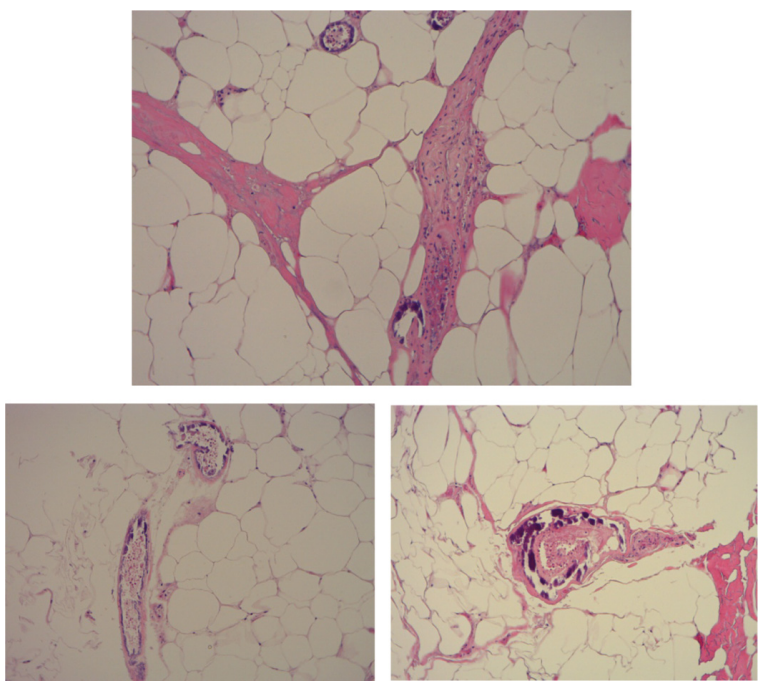

Figure I Skin biopsy showing calcium deposition in small arterioles.

skin necrosis (WISN), nephrogenic fibrosing dermopathy, ecthyma, cryofibrinogenemia, cellulitis, necrotizing fasciitis, neoplasms, coagulation disorders, and adverse drug effects, as well as disseminated intravascular coagulopathy with purpura fulminans and heparin-induced thrombocytopenia., ${ }^{5,9}$

Cutaneous manifestations of calciphylaxis include firm, extremely painful, well demarcated, purpuric plaques and nodules with surrounding livedo reticularis. Skin lesions eventually progress to soft-tissue ulceration, necrosis, and non-healing eschars. The most frequent sites are the lower extremities in roughly $90 \%$ of patients, but lesions can occur on the hands, fingers, tongue, trunk, abdomen, buttocks, and penis. ${ }^{1,5,7}$

\section{Case report}

A 56-year-old female patient presented after a fall, with worsening lower extremity edema. She was found to have

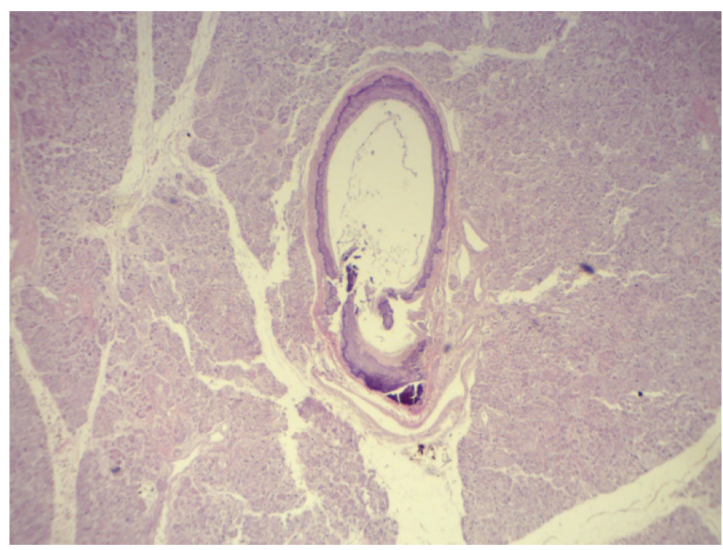

Figure 2 Calcified artery media in the pancreas.
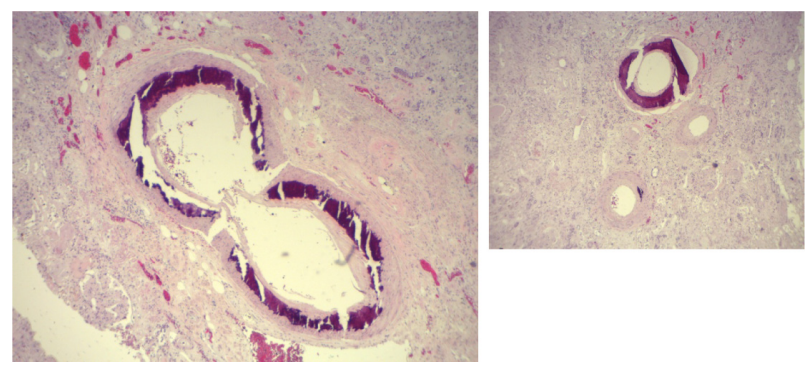

Figure 3 Calcified artery media in the kidneys.

acute-on-chronic kidney injury $(7.46 \mathrm{mg} / \mathrm{dL}$ on baseline creatinine of $2.42 \mathrm{mg} / \mathrm{dL}$ ). Past medical history was significant for diabetes mellitus type II and diabetic neuropathy, morbid obesity (body mass index $=48 \mathrm{~kg} / \mathrm{m}^{2}$ ), deep venous thrombosis, and pulmonary embolism, receiving warfarin for 2 years and 9 months, dyslipidemia, hypertension, chronic kidney disease stage IV, and peripheral vascular disease status post-amputation of the left toe 5 months earlier. Workup for acute kidney injury (AKI) was conducted, excluding post obstructive, prerenal, vasculitis, and multiple myeloma. The patient had a drop in hemoglobin; warfarin was withheld for 4 days on suspicion of blood loss and then restarted on day 6 (international normalized ratio $[\mathrm{INR}]=1.6$ reaching 1.3 ) after placement of an Ash catheter and initiation of dialysis with INR target in the range of 2-3, which was maintained throughout the entire hospital stay.

The patient developed a right foot blister on day 7 and bilateral thigh blisters on day 10 (Figure 4) that were
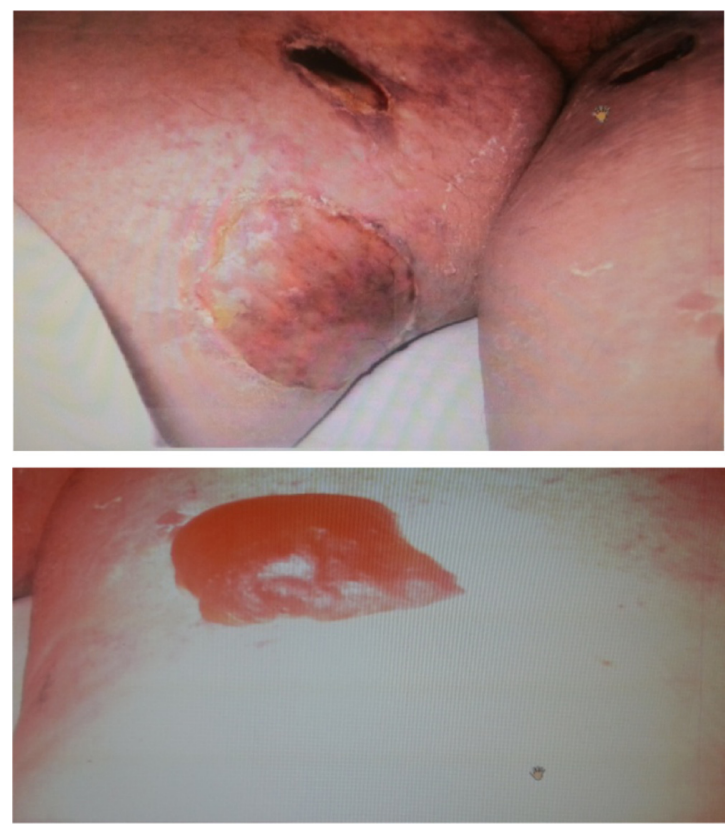

Figure 4 Day 10: thigh bullae and ulcerated skin. 
attributed initially to volume overload. Laboratory values were as follows: serum calcium (Ca) $7.4 \mathrm{mg} / \mathrm{dL}$, albumin $2.9 \mathrm{~g} / \mathrm{dL}$, inorganic phosphorus $10.3 \mathrm{mg} / \mathrm{dL}$, creatinine $7.68 \mathrm{mg} / \mathrm{dL}$, blood urea nitrogen (BUN) $98 \mathrm{mg} / \mathrm{dL}$, erythrocyte sedimentation rate (ESR) $122 \mathrm{~mm} / \mathrm{hr}$, intact parathyroid hormone (PTH) $368 \mathrm{pg} / \mathrm{mL}$, glucose $109 \mathrm{mg} / \mathrm{dL}$. The patient had significant proteinuria of $8,456 \mathrm{mg} / \mathrm{g}$, attributed to diabetic nephropathy (glycated hemoglobin $\left[\mathrm{HbA}_{1 \mathrm{c}}\right]$ 5.2\%). Total bilirubin was $0.5 \mathrm{mg} / \mathrm{dL}$, alkaline phosphatase was $65 \mathrm{IU} / \mathrm{L}$, aspartate aminotransferase (AST) was $15 \mathrm{IU} / \mathrm{L}$, and alanine aminotransferase (ALT) was 24 IU/L.

The skin became mottled and the lesions worsened progressively over 3 days to become necrotic eschars (Figure 5). Similar lesions developed over the lower extremities, flanks, and lower abdomen (Figure 6). Extended workup for vasculitis, autoimmune disorders, and coagulopathies was conducted and all were negative: anti-nuclear antibodies (ANA), anti-smith antibodies, anti-double-stranded DNA (dsDNA), anti-ribonucleoprotein (RNP) antibody, anti-neutrophil cytoplasmic antibodies (ANCA) (proteinase-3 AB and myeloperoxidase AB), Sjögren A and Sjögren B antibodies, C3 and C4 complement level, immunoglobulin (Ig)G anti-platelet factor (PF)-4, lupus anticoagulant, anti-cardiolipin IgG and IgM, anti-phospholipid IgM IgG antibodies, $\beta 2$ glycoprotein I IgG IgM IgA antibodies, hepatitis serologies for hepatitis C and $\mathrm{B}$ virus, and workup for multiple myeloma. Protein $\mathrm{C}$ function was $33 \%$, expected secondary to Coumadin therapy. Protein S activity, antithrombin III, IgA-IgM-IgG levels were all normal.

The patient became septic, with persistent leukocytosis and low-grade fever, along with worsening of skin lesions (Figure 7), with white blood count of $26 \mathrm{TH} / \mathrm{mm}^{3}$, platelet count of $264 \mathrm{TH} / \mathrm{mm}^{3}$, albumin of $1 \mathrm{~g} / \mathrm{dL}$,
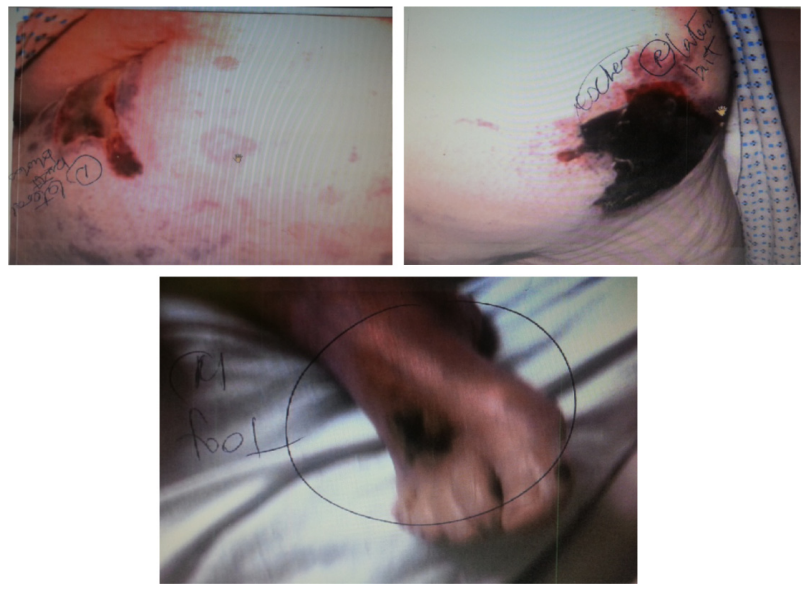

Figure 5 Day 14: necrotic and eschar lesion.
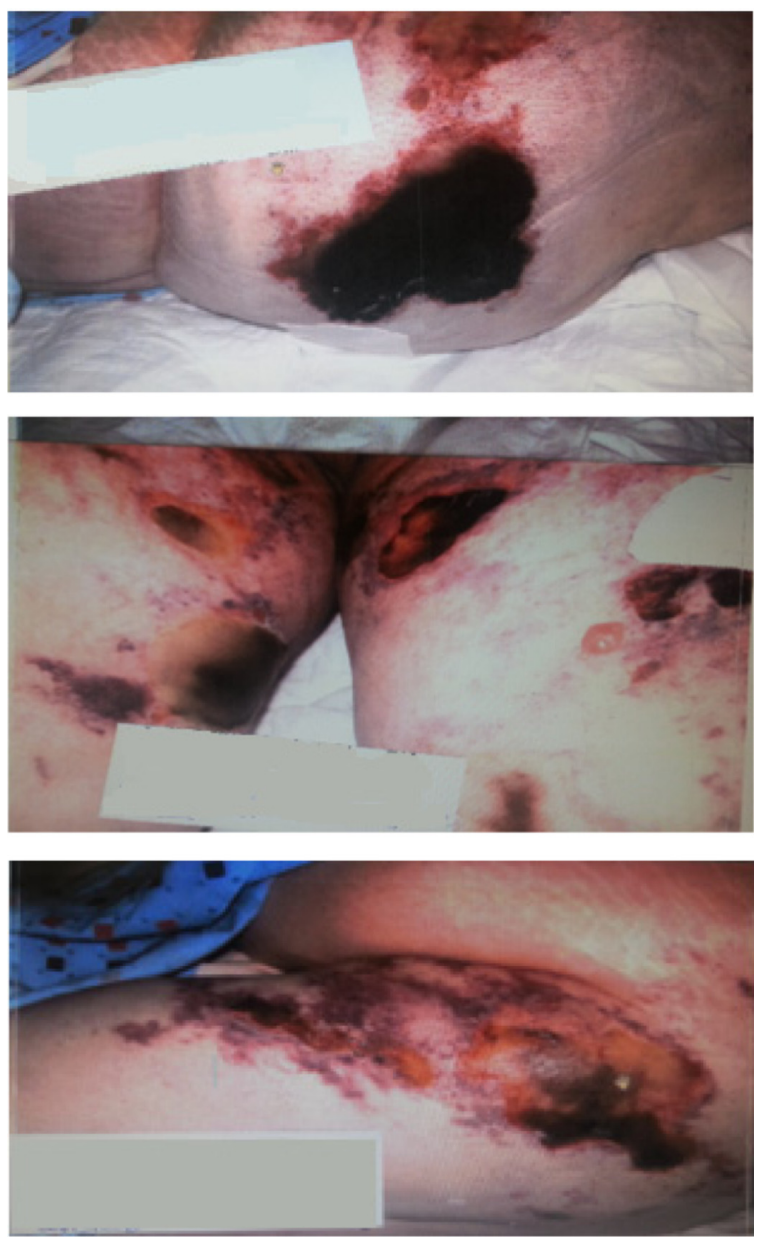

Figure 6 Day 17: worsening necrotic lesion on extremities, flanks and lower abdomen.

AST of $38 \mathrm{IU} / \mathrm{L}$, ALT of $37 \mathrm{IU} / \mathrm{L}$, total bilirubin (Tbil) of $0.5 \mathrm{mg} / \mathrm{dL}$, and alkaline phosphatase of $124 \mathrm{IU} / \mathrm{L}$.

The patient had eschar lesions on the right lower extremity $(75 \times 20 \mathrm{~cm})$, the left lower extremity $(75 \times 20 \mathrm{~cm})$, and an abdominal lesion $(10 \times 5 \times 5 \mathrm{~cm})$ (Figure 8$)$. The burn specialist provided care and the patient underwent skin debridement

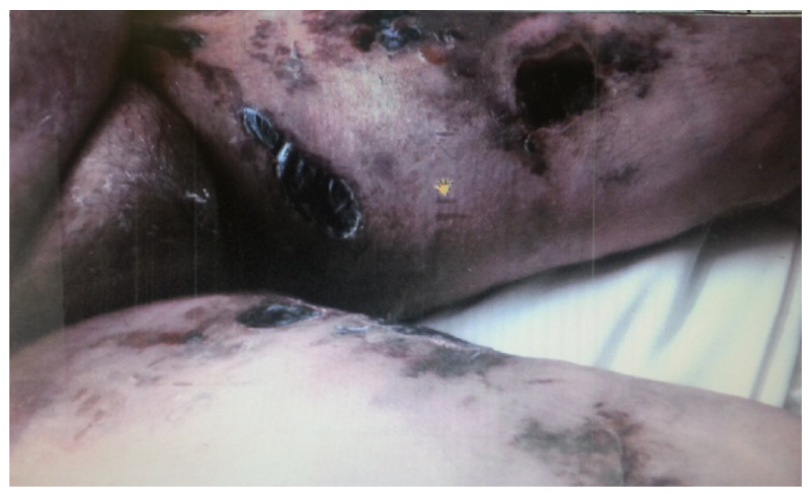

Figure 7 Progressively worsening lesions on bilateral thigh. 

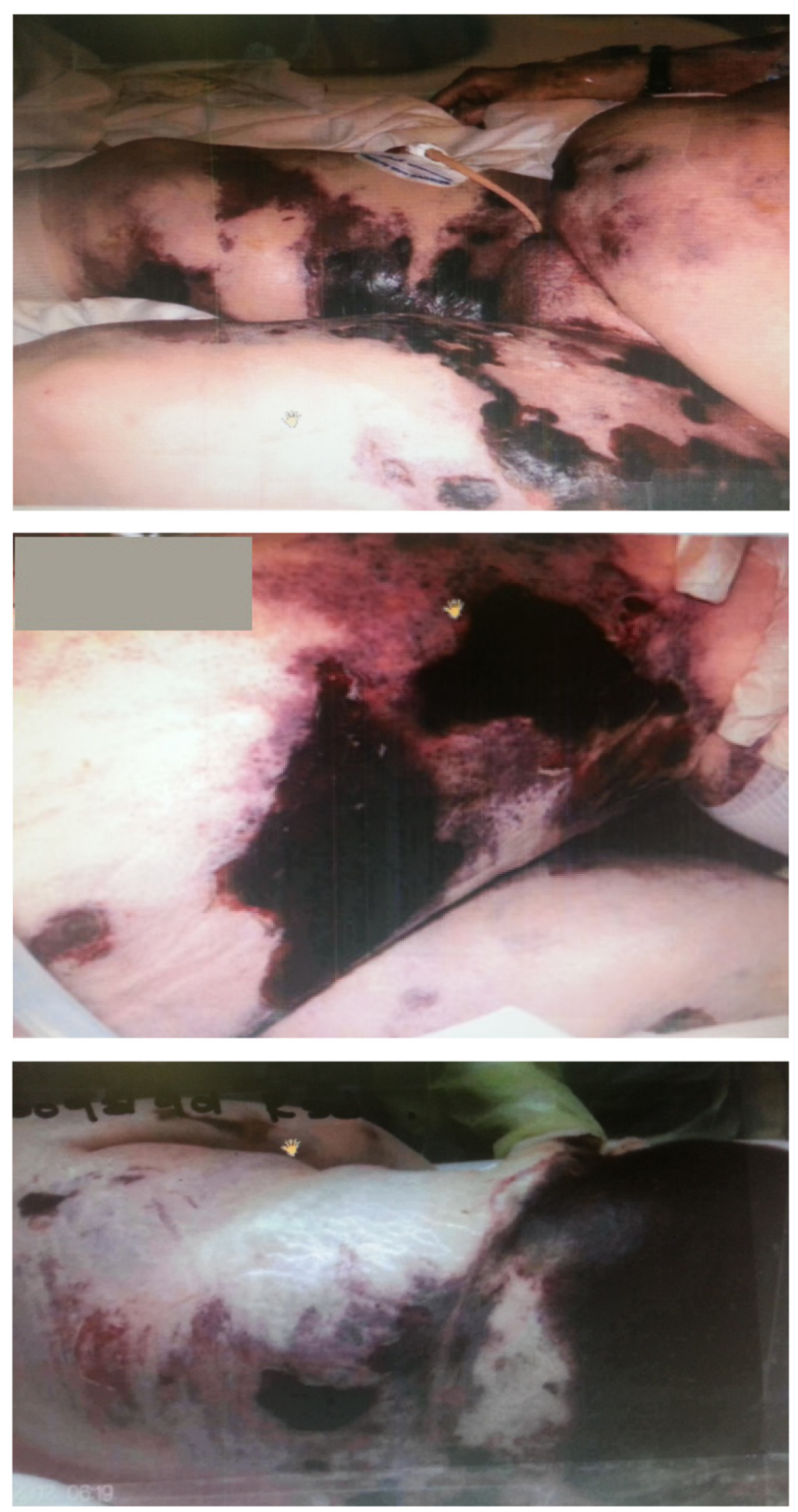

Figure 8 Diffuse skin necrotic eschar.

and wound care; however, all resuscitation efforts failed on day 42 .

A skin biopsy was performed and showed a portion of skin and subcutaneous tissue with diffuse necrosis and focal acute inflammation as well as multiple small arteries showing calcification of the tunica media. This pattern is strongly suggestive of calciphylaxis (Figure 1). Autopsy confirmed our diagnosis, with diffuse calcification of the splanchnic and renal arteries media.

WISN usually appears 3-10 days after starting warfarin, but can occur after many months to 15 years. ${ }^{5}$ WISN and calciphylaxis shares similar clinical findings and only biopsy of the skin can differentiate between the two conditions, showing a thrombotic occlusion in dermal, subcutaneous vasculature with hemorrhage. ${ }^{1}$ WISN lesions predominate in areas where there is relatively greater adipose tissue, for example, the breasts, thighs, hips, and buttock region. ${ }^{1}$

All workup for AKI and skin necrosis was conducted and vasculitis, multiple myeloma, coagulation disorder, heparin-induced thrombocytopenia, and cryoglobulinemia were excluded. The skin biopsy confirmed our diagnosis and excluded disseminated intravascular coagulation and other microthrombotic etiologies.

The pathogenesis of calciphylaxis is not well-known. It is related to many conditions such as malignancies, cirrhosis, primary hyperparathyroidism, and secondary hyperparathyroidism as a result of short-bowel syndrome and Crohn's disease. ${ }^{5}$ Previous observational studies have suggested several risk factors, including hyperphosphatemia, hypercalcemia, low serum albumin levels, female gender, obesity, diabetes mellitus, calcium content of the skin, ${ }^{5}$ warfarin therapy, ${ }^{1,2,6,7}$ systemic corticosteroid use, and elevation in alkaline phosphatase. ${ }^{7}$ Clarifying the causality relationship of many coexistent conditions in end-stage renal disease is challenging.

Hayashi et $\mathrm{al}^{2}$ conducted a multivariate analysis and found that there was a 10.1-fold higher risk of calciphylaxis with warfarin therapy.

Cases of calciphylaxis have been reported as occurring in the absence of hyperparathyroidism and renal failure. , $^{2,7}$ These findings support the view of calciphylaxis as a final common endpoint of an independent pathway. Calciphylaxis is believed to occur as a product of culminating conditions and stimuli via a final common pathway involving the nuclear factor kappa-beta activation, leading to vascular calcification. ${ }^{1}$

Descriptive cross-sectional data in humans as well as experimental data in rodents report a positive correlation of vitamin $\mathrm{K}$ antagonists and vascular calcification, ${ }^{3}$ leading to wide concern regarding the use of warfarin in cardiovasculopathic patients, and the viewing of this disease as partly iatrogenic when it is not a well-known natural sequel of chronic kidney disease (such as renal bone disease or renal hypertension or renal anemia). ${ }^{6}$

Warfarin therapy provokes an unbalanced pro- and anti-calcification factors, ${ }^{6}$ by inhibiting a matrix G1A protein responsible for inhibiting the mineralization of tissues. Matrix G1A protein is an 84 amino acid vitamin $\mathrm{K}$ dependent that is activated by carboxylation of glutamate residues. ${ }^{6,7,9}$ In rat models, the disruption of this protein led to extensive vascular calcification, ${ }^{6,7}$ and this possibly occurs in patients receiving long-term warfarin therapy. ${ }^{6}$ 
Retrospectively, vitamin K supplementation can lead to suppression of the calcification tendency. ${ }^{3}$

There are two subtypes of vitamin $\mathrm{K}$ : vitamin $\mathrm{K} 1$ is the most important for the activation of hepatic clotting factors, and vitamin $\mathrm{K} 2$ is involved in the inhibition of calcium deposition in the vasculature. ${ }^{7}$ Genetic variation and differential gamma-carboxylation at the glutamate residues is thought to be responsible for the varying phenotypes and susceptibility to vascular calcification. ${ }^{6-8}$

As this is a multifactorial disease, multifactorial treatment may be a successful intervention tool., , $^{3}$

Supportive treatment includes wound and pain management. Some success has been achieved with hyperbaric oxygen and intravenous sodium thiosulfate therapy. Correction of hypercalcemia and hyperphosphatemia is essential for treatment. Parathyroidectomy may benefit patients with refractory hyperphosphatemia. ${ }^{5}$

We hypothesize that the reintroduction of warfarin creates an imbalance favoring calcification in the vessels in previously sensitized conditions, which set our patient up for a catastrophic acceleration of vascular calcification.

Understanding the pathophysiology of this process will certainly enhance our treatment approach and reduce the morbidity and mortality of this devastating condition.

\section{Disclosure}

The authors report no conflicts of interest in this work.

\section{References}

1. Hafiji J, Deegan P, Brais R, Norris P. Warfarin-induced calciphylaxis successfully treated with sodium thiosulphate. Australas $J$ Dermatol. 2013;54:133-135.

2. Hayashi M, Takamatsu I, Kanno Y, et al; Japanese Calciphylaxis Study Group. A case-control study of calciphylaxis in Japanese end-stage renal disease patients. Nephrol Dial Transplant. 2012;27:1580-1584.

3. Brandenburg VM, Kramann R, Specht P, Ketteler M. Calciphylaxis in CKD and beyond. Nephrol Dial Transplant. 2012;27:1314-1318.

4. Jean G, Terrat JC, Vanel T, et al. [Calciphylaxis in dialysis patients: to recognize and treat it as soon as possible.] La calciphylaxie chez le patient dialysé : la reconnaître pour la traiter aussitôt que possible. Nephrol Ther. 2010;6:499-504. French.

5. Chacon G, Nguyen T, Khan A, Sinha A, Maddirala S. Warfarin-induced skin necrosis mimicking calciphylaxis: a case report and review of the literature. J Drugs Dermatol. 2010;9:859-863.

6. Asobie N, Wong E, Cook MG. Calciphylaxis in a diabetic patient provoked by warfarin therapy. Clin Exp Dermatol. 2008;33:342-344.

7. Banerjee C, Woller SC, Holm JR, Stevens SM, Lahey MJ. Atypical calciphylaxis in a patient receiving warfarin then resolving with cessation of warfarin and application of hyperbaric oxygen therapy. Clin Appl Thromb Hemost. 2010;16:345-350.

8. Cadavid JC, DiVietro ML, Torres EA, Fumo P, Eiger G. Warfarininduced pulmonary metastatic calcification and calciphylaxis in a patient with end-stage renal disease. Chest. 2011;139:1503-1506.

9. Huang YC, Chou CY, Sue YM, Hu CH. Warfarin-induced calciphylaxis in a chronic hypercalcemic patient. Indian J Dermatol Venereol Leprol. 2013;79:135.
International Journal of General Medicine

\section{Publish your work in this journal}

The International Journal of General Medicine is an international, peer-reviewed open-access journal that focuses on general and internal medicine, pathogenesis, epidemiology, diagnosis, monitoring and treatment protocols. The journal is characterized by the rapid reporting of reviews, original research and clinical studies across all disease areas.

\section{Dovepress}

A key focus is the elucidation of disease processes and management protocols resulting in improved outcomes for the patient. The manuscript management system is completely online and includes a very quick and fair peer-review system. Visit http://www.dovepress.com/ testimonials.php to read real quotes from published authors. 